\title{
Epidemiology of Non-Specific Back Pain in Children and Adolescents: a Systematic Review of Observational Studies
}

\author{
Lina Robalo ${ }^{1 *}$, Eduardo Cruz ${ }^{1}$ and Carla Nunes ${ }^{2}$
}

${ }^{1}$ Department of Physiotherapy, School of Health Care of the Setúbal Polytechnic Institute, Setúbal, Portugal

${ }^{2}$ Epidemiology and Statistics Group, National School of Public Health, Universidade Nova de Lisboa, Lisboa, Portugal

\begin{abstract}
Objectives: The aim of this study was to determine the prevalence and incidence of NSBP, and to identify its predisposing factors in children and adolescents. Study Design: Systematic review.

Materials and methods: A review of English articles was performed between 2005 and March 2012 using the following databases: PubMed, CINAHL and Web of Science. Inclusion criteria: published in peer-reviewed journals, written in English, samples aged between 6 and 18 years, with NSBP, and contained information of prevalence, incidence or predisposing factors. Two independent reviewers were involved in all phases. The methodological quality was assessed, using a standardized instrument.

Results: From the 1087 studies identified, only 35 fulfilled the inclusion criteria. Their methodological quality showed an average score of 10,32 out of 15. Great variability's in the definition of NSBP and in reported prevalence periods were found. Meta-analysis suggest NSBP prevalence's of $24,33 \%(95 \% \mathrm{Cl}: 18,22 \%-31,7 \%)$ - last month; between 17 , $4 \%$ and $51,3 \%$ - last 3 months; between $15,6 \%$ and $61,1 \%$ - last 6 months, between 17, $1 \%$ e $54,1 \%$ - last year. The results regarding the incidence of NSBP were not conclusive, nor was it possible to identify consistent and conclusive evidence in the associations between NSBP and the different analyzed factors.
\end{abstract}

Conclusions: The results presented in this study indicate a relatively high prevalence of NSBP in young population. There is a scarcity of studies concerning predisposing factors and also disagreements in the results. Further research is required, using prospective cohort designs.

Keywords: Back pain; Children/adolescents; Prevalence; Incidence; Predisposing factors; Systematic review

\section{Introduction}

Non-specific back pain (NSBP), defined as pain without specific cause or pathology [1], is a common complaint among young people that has been related with low back pain in adults [2]. Several studies have reported that the first symptoms of NSBP took place during childhood and adolescence, and continue into adulthood [2,3], with established associations between back pain in children and adults [4-6]. Recent research findings also showed that a great percentage of adults who search for health care services due to back pain, refer to having had pain episodes in their adolescence [2,3]. Accordingly, the history of back pain appears in the literature as a strong indicator of back pain in adulthood.

In the last decade research studies indicated that the prevalence of NSBP in the early stages of life has increased significantly and is now close to the percentage found in adulthood [4,7-10]. The most recent review of the incidence and prevalence of low back pain in the children and adolescents (aged 7-18 years) included 35 studies, and founded that the prevalence of pain varied between 7 and $62 \%$ [11]. A metaanalysis conducted by McBeth and Jones [12], reported a prevalence of low back pain in adolescents of approximately $33 \%$. Moreover, the prevalence may be underestimated due to the absence of a specific diagnosis [13].

Despite its unknown etiology a great variety of potential predisposing factors have been significantly associated with back pain in this population, including environmental, genetic, mechanic, behavioral and psychosocial [8]. Accordingly, the development of back pain in early stages of life has been often related to the relationship between the influence of the environment where the adolescent lives (e.g. school and home), the intrinsic risk factors and lifestyle [14].
However, the specific contribution of each factor for back pain, the way they interact, the multifactorial nature of the NSBP, and the methodological flaws associated with the study designs such as the lack of longitudinal studies, has limited the knowledge of the causal relationship between predisposing factors and back pain [15].

Therefore to better understand the epidemiology of NSBP in children and adolescents, this systematic review aimed to identify the prevalence and incidence of non-specific back pain in children and adolescents, and to identify predisposing factors for NSBP.

\section{Materials and Methods}

This review followed the Meta-analysis of Observational Studies in Epidemiology group (MOOSE) recommendations for reporting metaanalyses of observational studies [16].

Three electronic databases were searched (PubMed- MEDLINE, CINAHL and Web of Science) using the following combination of keywords: (child ${ }^{\star}$ OR adolescent ${ }^{\star}$ OR schoolchild ${ }^{\star}$ OR student ${ }^{\star}$ ) AND (thoracic spine OR dorsal spine OR lumbar spine OR back OR cervical spine) AND (pain OR discomfort OR back pain OR musculoskeletal

*Corresponding author: Robalo L, Epidemiology and Statistics Group, National School of Public Health, Universidade Nova de Lisboa, Lisboa, Portugal, Tel: 351265709398; E-mail: lina.robalo@ess.ips.pt

Received June 11, 2015; Accepted June 24 2015; Published June 29, 2015

Citation: Robalo L, Cruz E, Nunes C (2015) Epidemiology of Non-Specific Back Pain in Children and Adolescents: a Systematic Review of Observational Studies. J Nov Physiother 5: 266. doi:10.4172/2165-7025.1000266

Copyright: @ 2015 Robalo L, et al. This is an open-access article distributed under the terms of the Creative Commons Attribution License, which permits unrestricted use, distribution, and reproduction in any medium, provided the original author and source are credited. 
disorder) AND (causality OR cohort study OR cross-sectional study OR epidemiology OR epidemiologic factor ${ }^{*}$ OR follow-up study OR incidence OR incidence study OR prevalence OR prevalence study OR prospective study OR risk OR risk factor ${ }^{*}$ OR survey) NOT (arthritis OR fractures OR scoliosis OR rheumatic disorders).

Inclusion criteria included articles published in peer-reviewed journals, in English language, between January 2005 and March 2012 as well as their reference lists. Titles and abstracts of eligible articles were independently screened by two reviewers (LR; MJ) using the following inclusion criteria:

1. The study design had to be a cohort, case-control, or crosssectional.

2. Study samples should be aged 6 to 18 years, withdrawn from the general population, with NSBP. Samples from specific populations (e.g., practicing a specific sport, obese population or others) were excluded.

3. Non-specific thoracic, dorsal, upper back, mid-back or low back pain had to be assessed in the study. Studies that comprised only individuals with cervical and shoulder pain were excluded. Studies reporting back pain characteristics among a cohort of individuals with known pathologies (e.g. osteoporosis, fractures) or diagnosed structural deformities (e.g. scoliosis) were also excluded.

4. Studies had to report data at least one of the following parameters: prevalence, incidence, predisposing factors for back pain. Studies reporting lifetime prevalence were excluded because children easily forget the episodes of back pain and therefore it is considered unreliable $[17,18]$.

5. The outcome of the studies should include the examination of associations between predisposing factors and the presence of back pain. Outcomes could be self-reported or clinically evaluated.

Disagreements between reviewers were resolved by consensus. When disagreement persisted, a third independent reviewer (EC) was consulted and a final decision was made. The full text of potentially relevant papers was then assessed against the same criteria. A flowchart of the selection process is shown in Figure 1.

\section{Study quality assessment}

Selected articles were evaluated for methodological quality, by two independent reviewers (LR; EC), using the Critical Review Form Quantitative Studies [19]. Based on 15 dichotomous quality appraisal criteria (yes - 1/no - 0), there were assessed methodological bias (including, selection, measurement and confounding bias), clinical importance of the results, conclusions and implications for clinical practice.

A quantitative score was obtained by summing the total of 15 criteria. Disagreements between the reviewers on individual items were identified and discussed and a third reviewer $(\mathrm{CN})$ was consulted if necessary.

\section{Data extraction and analysis}

Two independent reviewers (LR; CN) extracted the data using a

Medline ( $\mathrm{n}=235)$; CINAHL ( $\mathrm{n}=212)$; Web of Science $(\mathrm{n}=640)=1087$ citations

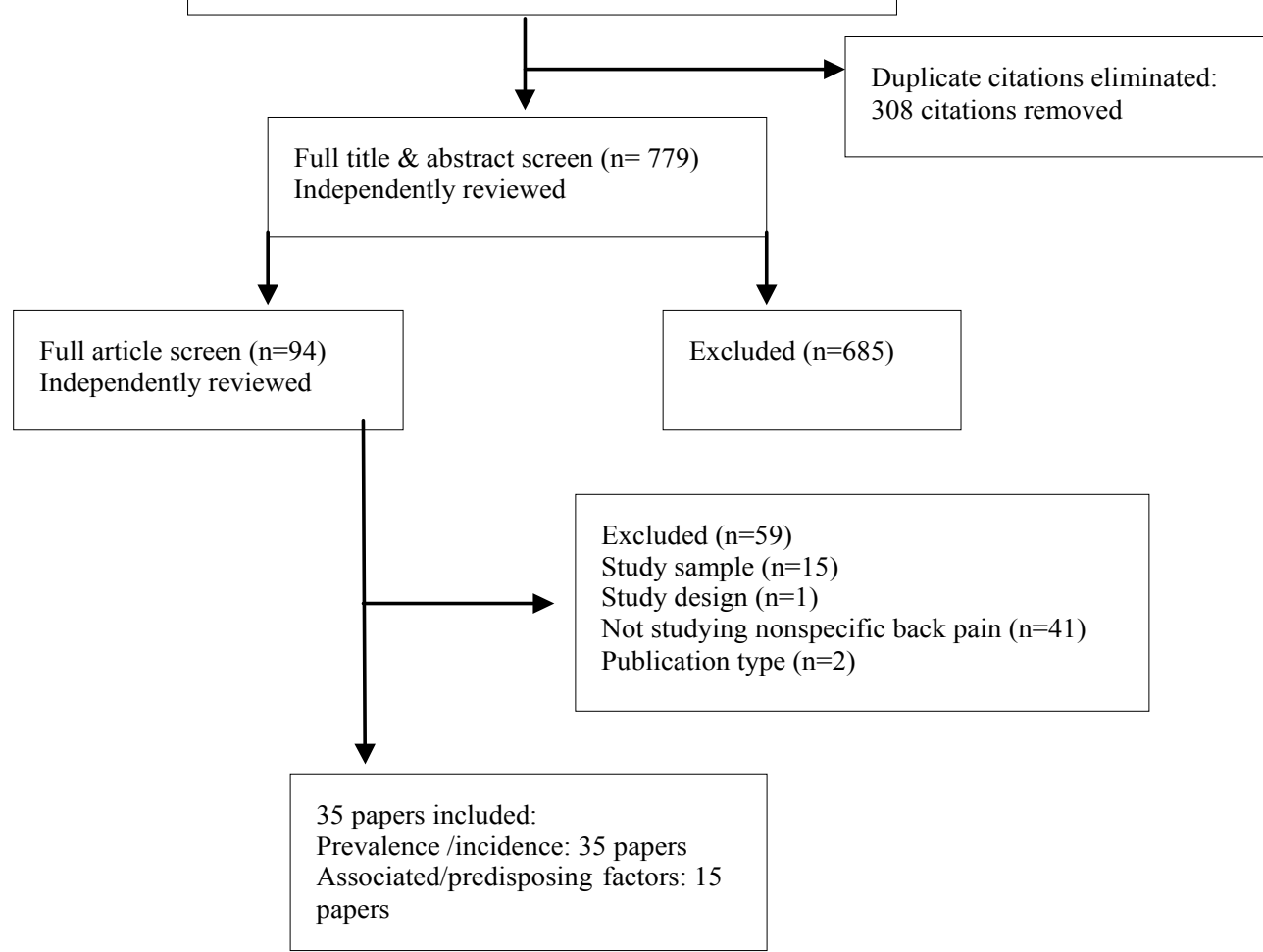

Figure 1: Flowchart of the search strategy and selection of studies to estimate prevalence/incidence and association between back pain and predisposing factors 
customized form. The extracted data consisted of: authors, study design, study population, participation rate, sample characteristics (size, age, nationality), outcomes, data collection tools, and study's results (prevalence rate, correlations values between predisposing factors and back pain; and risk estimations). Data extraction was separately conducted for incidence and prevalence rates and for predisposing factors for back pain.

To conduct the meta-analysis, studies were grouped according to time prevalence in 1-month, 3-months, 6-months and 1-year prevalence, respectively. In what regards to pain location, the prevalence was estimated on the basis of the prevalence values related to pain in the back or any pain in the spine/back.

For each period of prevalence (one, three or six months, and one year) the differences in the duration of pain, or age intervals were not considered. When the prevalence was presented by gender or age, a global weighting prevalence was computed. Since episodes of back pain are easily forgotten by the children $[17,18]$, statistical analyses of the association between back pain and risk factors were limited to 1 month prevalence of pain.

\section{Statistical analysis}

Extracted data was analysed for prevalence, incidence and predisposing factors, grouped by different time periods (1-month, 3 and 6 month and 1-year). When possible, study results were pooled in statistical meta-analysis using the Comprehensive Meta Analysis software 2.0 [20]. Heterogeneity was assessed through the Q statistics and the I2 index, with the I2 representing the percentage of degree of variation among studies ( 0 means that heterogeneity was absent, and larger I2 indicates a higher probability of heterogeneity).

Fixed effects models were used to compute mean prevalence rates and $95 \%$ confidence intervals $(95 \% \mathrm{CI})$. When heterogeneity was present random effects models were used. Publication biases were tested by the Funnel Plot and Begg's and Egger's tests.

When Meta-Analysis was not possible, because of the absence of information or due to heterogeneity between studies, a narrative synthesis of the findings was carried out.

\section{Results}

The literature search resulted in 1087 citations, but only 35 studies met the inclusion criteria and were included for full review and data extraction.

\section{Study characteristics}

Twenty-one studies were conducted in Europe (60\%), 7 were carried out in Oceania, 4 in Asia, 2 in Africa and 1 in North America, all including males and female and with ages between 6 to 18 years. Sample size ranged from 55 [21] to 34,423 participants [22].

There was considerable variation in the methods used to define back pain, ranging from pain location (any pain on the back or spine, low back, upper back, mid back, thoraco-lumbar back), pain duration and frequency of the episode, pain severity and prevalence period.

The most common prevalence periods were 1- month (22 studies) [8,21-41], 6-months (7 studies) [34,42-47], followed by 3-months [48$51]$ and 1-year prevalence $[9,31,34,52]$ with four studies each. Table 1 summarizes the characteristics of the included studies (author/year, study design, sample characteristics, the pain definition used and measuring tools)

\section{Methodological quality assessment}

Of the 35 papers included in the review, 29 (83\%) were cross-

\begin{tabular}{|c|c|c|c|c|c|c|}
\hline \multirow{2}{*}{ Author/year } & \multirow{2}{*}{ Design } & \multicolumn{3}{|c|}{ Sample characteristics } & \multirow{2}{*}{ Pain definitions (all self-reported) } & \multirow{2}{*}{ Measures tools } \\
\hline & & Nationality & $\mathbf{n}$ & Age & & \\
\hline Andersen, LB, et al. (2006)*[23] & 1 & Danish & 9413 & 17,1 & $\begin{array}{l}\text { Low or mid back pain in the present or during the last } \\
\text { month }\end{array}$ & Questionnaire \\
\hline Auvinen, J. et al. (2008) [42] & 1 & Finish & 5999 & $15-16$ & Low back pain during the last 6 months & Questionnaire \\
\hline Auvinen, JP. et al. (2010) [43] & 2 & Finish & 9215 & 16 and 18 & Low back pain during the last 6 months & Questionnaire \\
\hline Auvinen, JP. et al. (2008) [44] & 1 & Finish & 6945 & 16 & Low back pain during the past 6 months & Questionnaire \\
\hline Ayanniyi, O. et al. (2011) [24] & 1 & Nigerian & 3185 & 18-Oct & Present back pain & Questionnaire \\
\hline Chiang, H. et al. $(2006)^{\star}[21]$ & 1 & American & 55 & $13-14$ & Low back pain in the previous two weeks & Questionnaire \\
\hline $\begin{array}{l}\text { Cudre-Mauroux, N. et al. } \\
(2006)^{*}[25]\end{array}$ & 1 & Swiss & 128 & 12-Aug & Low back and upper pain in the last week & Questionnaire/ drawing figure \\
\hline \multirow{2}{*}{$\begin{array}{l}\text { Diepenmaat, ACM, et al. } \\
(2006)^{\star}[26]\end{array}$} & \multirow{2}{*}{1} & \multirow{2}{*}{ Dutch } & \multirow{2}{*}{3485} & \multirow{2}{*}{ 16-Dec } & \multirow{2}{*}{ Low pain $\geq 4$ days in the last month } & Questionnaire/ \\
\hline & & & & & & manikin pictures \\
\hline $\begin{array}{l}\text { Erne, C, and Elfering, A (2011) } \\
\text { [27] }\end{array}$ & 1 & Swiss & 189 & 13-Oct & $\begin{array}{l}\text { Low back pain/upper back pain for } 1 \text { day or longer in } \\
\text { the last } 4 \text { weeks }\end{array}$ & Questionnaire/ drawing figure \\
\hline Geldhof, E. et al. $(2007)^{\star}[28]$ & 1 & Belgium & 105 & $8,5-12,5$ & $\begin{array}{l}\text { Occurrence of pain or discomfort, continuous or } \\
\text { recurrent, in the thoraco-Iumbar zone in the past } \\
\text { week }\end{array}$ & Questionnaire/ drawing figure \\
\hline \multirow{2}{*}{ Grimmer, K. et al. (2006a) [14] } & \multirow{2}{*}{2} & \multirow{2}{*}{ Australian } & \multirow{2}{*}{434} & \multirow{2}{*}{$13-17$} & \multirow{2}{*}{ Low back pain in the previous week } & Questionnaire/ \\
\hline & & & & & & body chart \\
\hline \multirow{2}{*}{ Grimmer, K. et al. (2006b) [29] } & \multirow{2}{*}{2} & \multirow{2}{*}{ Australian } & \multirow{2}{*}{436} & \multirow{2}{*}{$13-17$} & \multirow{2}{*}{ Upper back pain in the previous week } & Questionnaire/ \\
\hline & & & & & & body chart \\
\hline \multirow{2}{*}{ Hakala, PT. et al. (2006) [45] } & \multirow{2}{*}{1} & \multirow{2}{*}{ Finish } & \multirow{2}{*}{6003} & \multirow{2}{*}{$\begin{array}{l}14,16 \\
\text { and } 18\end{array}$} & \multirow{2}{*}{$\begin{array}{l}\text { Low back pain during de past } 6 \text { months about once } \\
\text { a month }\end{array}$} & Questionnaire/ \\
\hline & & & & & & body chart \\
\hline Heaps, N. et al. $(2011)^{*}[30]$ & 1 & Australian & 1608 & 14 & Back Pain in the past month & Questionnaire \\
\hline Jordaan, R. et al. $(2005)^{\star}[31]$ & 1 & $\begin{array}{l}\text { South- } \\
\text { African }\end{array}$ & 1123 & $13-18$ & Low back pain or discomfort now & Questionnaire/ drawing figure \\
\hline Kaspiris, A, et al. (2010) [52] & 1 & Greece & 692 & 14-Jul & Low back pain in the last year & Questionnaire/ picture \\
\hline
\end{tabular}


Citation: Robalo L, Cruz E, Nunes C (2015) Epidemiology of Non-Specific Back Pain in Children and Adolescents: a Systematic Review of Observational Studies. J Nov Physiother 5: 266. doi:10.4172/2165-7025.1000266

Page 4 of 8

\begin{tabular}{|c|c|c|c|c|c|c|}
\hline Kjaer, P. et al. (2011) [32] & 2 & Greece & 479 & $\begin{array}{l}9,13 \text { and } \\
15\end{array}$ & $\begin{array}{l}\text { Spinal pain in the moment, in the past week, or within } \\
\text { the past month }\end{array}$ & Interview \\
\hline \multirow{2}{*}{ Korovessis, et al. (2010) [46] } & \multirow{2}{*}{1} & \multirow{2}{*}{ Greece } & \multirow{2}{*}{688} & \multirow{2}{*}{$14-18$} & \multirow{2}{*}{$\begin{array}{l}\text { Low back pain or discomfort in the previous } 6 \\
\text { months }\end{array}$} & Questionnaire/ \\
\hline & & & & & & Pain drawing manikin \\
\hline Masiero, et al. (2008) [9] & 1 & Italian & 7442 & $13-15$ & Low back pain in the last year & Questionnaire \\
\hline Mikkonen, et al. (2008) [47] & 2 & Finish & 1987 & 16 and 18 & Low back pain during the past 6 months & $\begin{array}{l}\text { Questionnaire/Pain drawing } \\
\text { manikin }\end{array}$ \\
\hline Mogensen, et al. $(2007)^{\star}[33]$ & 1 & Danish & 439 & 13-Dec & $\begin{array}{l}\text { Back problems (pain in the day of the study, in the } \\
\text { week, or in the month preceding) in any area of the } \\
\text { spine }\end{array}$ & Questionnaire \\
\hline $\begin{array}{l}\text { Mohseni-Bandpei, MA. et al. } \\
(2007)^{\star}[34]\end{array}$ & 1 & Iran & 4813 & 14-Nov & Low back pain within last month & Questionnaire \\
\hline Murphy, et al. $(2007)^{\star}[8]$ & 1 & English & 679 & 14-Nov & $\begin{array}{l}\text { Low back and upper back pain within last month for } \\
1 \text { day or more }\end{array}$ & Questionnaire/ Manikin \\
\hline O'Sullivan, et al. (2008) [35] & 1 & Australian & 1608 & 14 & Back pain in the last month & Questionnaire \\
\hline Pellise, F. et al. (2009) [37] & 1 & $\begin{array}{l}\text { Spanish/ } \\
\text { Swiss }\end{array}$ & 1470 & 15 & Low back pain within last month for 1 day or more & Questionnaire/ Manikin \\
\hline Perry et al. (2009) ${ }^{\star 36}$ & 1 & Australian & 1608 & 14 & Back pain in the last month & Questionnaire \\
\hline Roth-Isigkeit, et al. (2005) [48] & 1 & Germany & 751 & 18-Jun & Back pain in the preceding 3 months & Questionnaire \\
\hline Sato, et al. $(2008)^{\star}[21]$ & 1 & Japan & 34423 & 15-Sep & Low back pain (in the day of the study) & Questionnaire \\
\hline Sato, T. et al. (2011) [38] & 1 & Japan & 26766 & 15-Sep & Low back pain (in the day of the study) & Questionnaire \\
\hline Skoffer, (2007) [49] & 1 & Danish & 546 & $15-16$ & Low back pain in the preceding 3 months & Questionnaire \\
\hline Trevelyan, and Legg, $(2011)^{\star}[40]$ & 1 & $\begin{array}{l}\text { New } \\
\text { Zealand }\end{array}$ & 245 & 14-Nov & $\begin{array}{l}\text { Experiencing back pain within last } 7 \text { days or last } \\
\text { month for } 1 \text { day or more }\end{array}$ & Questionnaire/ Manikin \\
\hline Trevelyan, and Legg, $(2010)^{\star}[39]$ & 1 & $\begin{array}{l}\text { New } \\
\text { Zealand }\end{array}$ & 245 & 14-Nov & $\begin{array}{l}\text { Experiencing back pain within last } 7 \text { days or last } \\
\text { month for } 1 \text { day or more }\end{array}$ & Questionnaire/ Manikin \\
\hline Turk, et al. (2011)[50] & 1 & Slovenia & 190 & $\begin{array}{l}11-15 \\
\text { and } 17-18\end{array}$ & $\begin{array}{l}\text { Pain or discomfort in the lower back in the last } 3 \\
\text { months for } 1 \text { day or more }\end{array}$ & Questionnaire \\
\hline Wedderkopp, et al. $(2009)^{\star}[41]$ & 2 & Danish & 364 & 9 and 12 & $\begin{array}{l}\text { Occurrence of pain or discomfort in the back in the } \\
\text { last month }\end{array}$ & Interview \\
\hline Yao, et al. Spine (2011) [51] & 1 & China & 2083 & 18-Oct & Back pain in the preceding 3 months & Questionnaire/ Manikin \\
\hline
\end{tabular}

*Studies included for the analysis of the results regarding predisposing factors for non-specific back pain.

Table 1: Characteristics of the included studies.

sectional surveys and $6(7 \%)$ were prospective cohort studies. The major limitations in the quality of the studies were related to response rates below $80 \%$, inadequate sample size justification, lack of information regarding informed consent or concerning with reliability and validity of the outcome measures used, poor description of the clinical implications of the results and misreport of the study's limitations. Strengths of the studies were related to appropriate report of the study design, statistical significance of the results and implications for clinical practice.

1-month back pain prevalence: Twenty-two studies reported 1-month prevalence. Assuming a fixed-effects model the NSBP prevalence estimated was $16,07 \%$ (95\%CI: $15,81 \%$; $16,33 \%$; $<<0,001$ ). Using a random-effects model the prevalence estimated was $24,33 \%$ (95\%CI: 18, 22\%; 31, 7\%; p <0,001). Homogeneity was not satisfied $(\mathrm{Q}=5796,038 ; \mathrm{p}<0,001 ; \mathrm{I} 2=99,67 \%)$. Forest Plot (with Random Effect model) is shown in Figure 2. Begg's and Egger's tests failed to identify publication bias (Begg's test, $\mathrm{p}=0,67$; Egger's test, $\mathrm{p}=0,1$ ). To measure the stability of the results, sensitivity analysis was used and the stability confirmed (Figure 2).

3-month, 6-month and 1-year back pain prevalence: From the 35 studies selected, 4 studies reported a 3-month prevalence, 7 a 6-month prevalence, and 4, one-year prevalence. NSBP prevalence for each period was estimated by a fixed- effects model with the following results: 3-months: 33, 74\% (95\%CI: 32, 18\%; 35, 33\%; p<0,001); 6 months: 42, 32 (95\%CI: 41, 78\%; 42, 86\%; p<0,001); 1-year: $21,93 \%$ (95\%CI: 21, 24\%; 22, 64\%; $\mathrm{p}<0,001)$ and with a random-effects model (3-months: $37,97 \%$ (95\%CI: 27,81\%; 49,31\%; p<0,001); 6 months: 38 ,
55 (95\%CI: 27, 14\%; 51, 37\%; p<0,001); 1-year: 25, 76\% (95\%CI: 16 , $67 \% ; 37,56 \% ; \mathrm{p}<0,001)$. Based on Q statistics and I2, homogeneity cannot be assumed (3-months: $\mathrm{Q}=104,2425$; $<<0,001$; $\mathrm{I} 2=97,12 \%$; 6- months: $\mathrm{Q}=3090,801 ; \mathrm{p}<0,001 ; \mathrm{I} 2=99,8 \%$; 1 year: $\mathrm{Q}=435,7774$; $\mathrm{p}<0,001 ; \mathrm{I} 2=99,31)$. Stability problems were identified in all the analysed periods and they have remained with the removal of any of the included studies. Based on these results it has been decided to carry out a narrative synthesis of the prevalence estimates rather than the meta-analysis.

\section{Narrative synthesis}

In the 3-months period, the NSBP prevalence ranged from $17,4 \%$ [51] to 51,3\% [49]. In the past 6 month the NSBP prevalence ranged from $15,6 \%$ [34] to $61,1 \%$ [44] and in the last year NSBP prevalence ranged from $17,4 \%$ [34] to 54, 1\% [31]. Table 2 shows the 3, 6 months and 1-year prevalence for NSBP according to the self-report period of back pain of NSBP assessed in each study and age.

\section{Back pain incidence}

Of the 35 studies analyzed only two studies reported incidence [15, 29]. Grimmer et al. followed a sample of 434 children during a period of 5 years (1999-2003), and found a percentage of new cases of 7,2\% for males and $10,4 \%$ for females [15].

In another longitudinal study conducted by the same research group, the authors followed a sample of 436 children, aged 13, during 5 years and founded that incidence decreases in females between 14 and 17 years of age, but increases in males, who present a higher incidence at the age of 16 [29]. 
Citation: Robalo L, Cruz E, Nunes C (2015) Epidemiology of Non-Specific Back Pain in Children and Adolescents: a Systematic Review of Observational Studies. J Nov Physiother 5: 266. doi:10.4172/2165-7025.1000266

\begin{tabular}{|c|c|c|c|c|c|}
\hline \multirow[t]{2}{*}{ Study name } & \multicolumn{5}{|c|}{ Statistics for each study } \\
\hline & $\begin{array}{c}\text { Event } \\
\text { rate }\end{array}$ & $\begin{array}{c}\text { Lower } \\
\text { limit }\end{array}$ & $\begin{array}{l}\text { Upper } \\
\text { limit }\end{array}$ & Z-Value & p-Value \\
\hline Andersen, LB, et al. 2006 & 0,327 & 0,318 & 0,337 & $-32,779$ & 0,000 \\
\hline Ayanniyi, O, et al. 2011 & 0,167 & 0,155 & 0,181 & $-33,813$ & 0,000 \\
\hline Chiang, $\mathrm{H}$, et al. 2006 & 0,345 & 0,232 & 0,479 & $-2,260$ & 0,024 \\
\hline Cudre-Mauroux, N, et al. 2006 & 0,226 & 0,162 & 0,306 & $-5,825$ & 0,000 \\
\hline Diepenmaat, ACM, et al. 2006 & 0,075 & 0,067 & 0,084 & $-41,032$ & 0,000 \\
\hline Erne, C, \& Elfering, A. 2011 & 0,153 & 0,108 & 0,212 & $-8,469$ & 0,000 \\
\hline Geldhof, E, et al. 2007 & 0,450 & 0,358 & 0,546 & $-1,023$ & 0,306 \\
\hline Grimmer, K. et al. $2006 \mathrm{~b}$ & 0,160 & 0,123 & 0,206 & $-10,529$ & 0,000 \\
\hline Heaps, N, et al.(2011). & 0,282 & 0,261 & 0,305 & $-16,863$ & 0,000 \\
\hline Jordaan, R. et al. 2005 & 0,127 & 0,107 & 0,149 & $-20,350$ & 0,000 \\
\hline Kjaer, P, et al. 2011 & 0,280 & 0,240 & 0,324 & $-8,885$ & 0,000 \\
\hline Mogensen, AM, et al. 2007 & 0,589 & 0,542 & 0,634 & 3,709 & 0,000 \\
\hline Mohseni-Bandpei, et al. 2007 & 0,144 & 0,134 & 0,154 & $-43,416$ & 0,000 \\
\hline Murphy, S, et al. 2007 & 0,220 & 0,190 & 0,253 & $-13,662$ & 0,000 \\
\hline O'Sullivan et al. 2008; Perry et al. 2008 & 0,281 & 0,260 & 0,303 & $-16,934$ & 0,000 \\
\hline Pellise et al. 2009 & 0,398 & 0,373 & 0,423 & $-7,766$ & 0,000 \\
\hline Sato et al. 2008 & 0,102 & 0,099 & 0,105 & $-122,141$ & 0,000 \\
\hline Sato et al. 2011 & 0,086 & 0,083 & 0,089 & $-108,412$ & 0,000 \\
\hline Trevelyan \& Legg 2010; Trevelyan \& Legg 2011 & 0,584 & 0,521 & 0,644 & 2,617 & 0,009 \\
\hline \multirow[t]{2}{*}{ Wedderkopp et al. 2009} & 0,435 & 0,385 & 0,486 & $-2,473$ & 0,013 \\
\hline & 0,243 & 0,182 & 0,317 & $-6,062$ & 0,000 \\
\hline
\end{tabular}

Event rate and $95 \% \mathrm{Cl}$
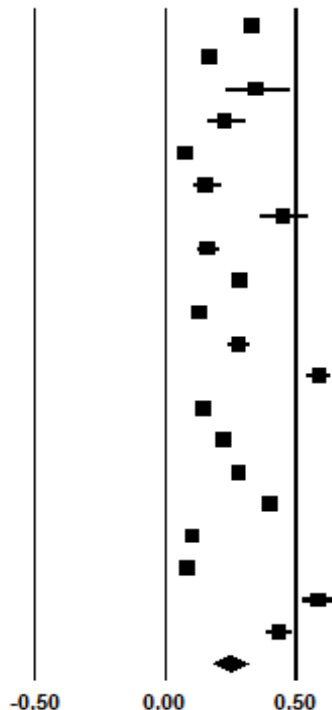

Favours B

Figure 2: 1-month prevalence for nonspecific back pain and 95\% confidence interval from the individual studies and Forest Plot (Random Effects Model).

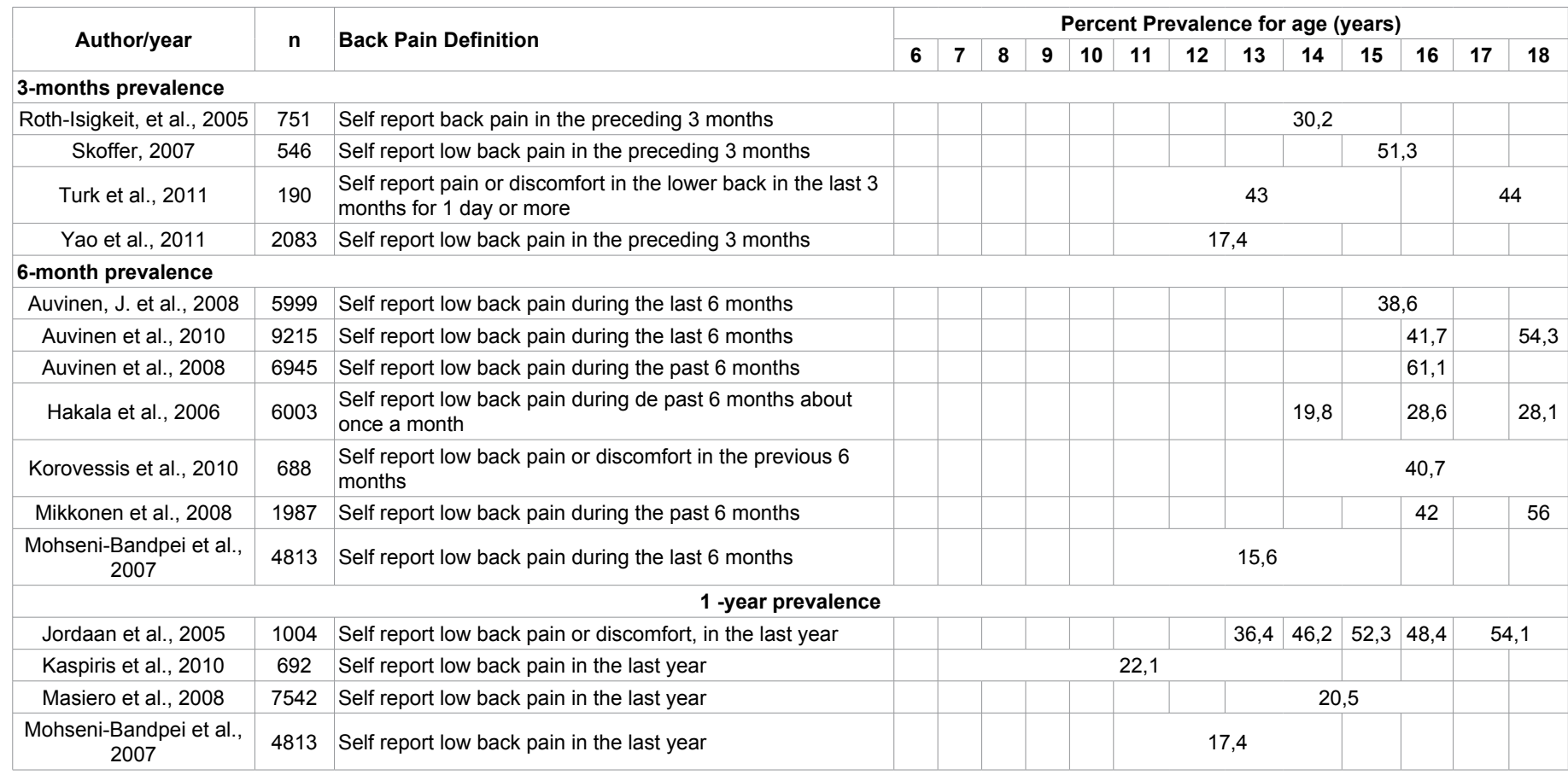

Table 2: 3-month, 6-month and 1-year prevalence of NSBP for children and adolescents aged 6 to 18 years.

Predisposing factors for nonspecific back pain in children and adolescents

Fifteen studies investigated different predisposing factors for back pain in children and adolescents. The potential predisposing factors included a multitude of factors that for clarity were grouped in 5 categories: 1) physical/anthropometric factors (age, gender, body mass index and physical qualities); 2) psychological and emotional factors (depression, psychological distress, etc); 3) Social and family factors (parents educational level; parents self-reported pain; familiar structure); 4) Lifestyles factors (Alcohol and tobacco consumption, physical activity); 5) and mechanical factors (postural behavior, school 
bag weight and transportation, time spending watching television, computer use).

In general, the inconsistency founded in the use of conceptual definitions and related measurement tools for the same variable and the multitude of variables of very different natures that have been explored, limited the comparison between studies. Moreover, the examination of the relationship between these factors and NSBP showed conflicting results among studies.

Eleven studies looked for significant correlations between the physical/anthropometric factors and the self-report of BP. The findings of these studies showed conflicting evidence for age $[25,28,31,34]$, gender $[23,25,26,28,30,31,34,36,38]$, body mass index $[21,34,36]$ and physical qualities, such as muscle strength $[23,36]$ or muscle endurance [23], muscle control [25] or the maximum level of VO2 [23].

Three studies reported findings of significant association between a range of psychosocial and emotional factors and BP [26,30,40]. Significant associations with NSBP were found for "Internalizing and externalizing behavior" (both sexes), "self-worth" and "Family functioning" (girls only) [30], emotional symptoms and hyperactivity [40], depressive symptoms $[26,30]$ and stress experienced [26].

From the two studies that had explored the association between social and family factors and NSBP $[8,26]$, none had reported statistically significant findings. Lifestyles factors were analyzed in seven studies $[21,23,26,30,33,34,41]$. Heaps et al. [30] founded statistically significant associations between alcohol and tobacco consumption and NSBP. There were conflicting evidence about the relationship between the level of physical activity and NSBP [21,26,34,41]. No association was found between the practice of physical activity or sports and NSBP $[23,33]$.

Finally a number of mechanical factors were associated with NSBP. NSBP in children and adolescents has been shown to have a significant association with school bag carrying time [21], carrying the bag on one shoulder [40], twisting the back for more than $10 \mathrm{~min}$ during a class [8] and position and time spent watching television, or doing the homework [34]. Conflicting results have also been reported for the weight of the school bag $[8,34,40]$ and time spending watching television [26,34]. No association was founded between postural behavior [28] and computer use [26,34] with NSBP.

In summary, it was not possible to identify consistent and conclusive evidence of the association between back pain and the different predisposing factors reported in the literature.

\section{Discussion}

The purpose of this systematic review was to determine the prevalence and incidence of non-specific back pain in children and adolescents and to identify its predisposing factors.

A total of 35 studies specifically designed for children and adolescents with NSBP were included. Similar to previous reviews, this systematic review founded considerable methodological heterogeneity between studies, particularly related to the prevalence period and case definition $[11,15,17]$. The absence of a clear specification of the minimum episode duration required for a case to be counted limited a more conclusive understanding of the pain prevalence among children and adolescents. Recently, an international Delphi study concluded that definitions for prevalence studies of back pain should include, at least, the location of back pain, symptoms observed, time frame of the measure, and severity [53].
The period recommended for investigating back pain prevalence is the first month after its occurrence, because it has been suggested that children easily forget pain. This fact also has been associated with underestimate reports of pain prevalence [17,18]. Despite the limitations reported, back pain prevalence estimates presented in this systematic review are high and consistent with others reported in the literature of NSBP in children and adolescents $[11,15,17]$.

The small number of studies reporting NSBP incidence limited its analysis. From de 6 studies analysed only the studies from Grimmer and colleagues report incidence values [14,29]. Moreover one study refers to the annual incidence of Low Back Pain [14] and the other to the annual incidence of Upper Back Pain [29].

In summary, the methodological heterogeneity founded across the primary studies, as well as the scarcity of data available, restrained the possibility to conduct a more conclusive analysis, namely a Metaanalysis.

\section{Predisposing factors for nonspecific back pain}

Of the 35 studies included in this review, 15 aimed to identify predisposing factors for back pain in children and/ or adolescents. From the 15 studies identified, 14 were based in cross-sectional studies. This constitutes a major limitation to the studies' findings since this kind of design only allowed for the association between predisposing factors and NSBP to be examined. It is therefore not possible to establish any causal relationship between variables and outcome.

Another key finding of this review was the extent of heterogeneity in the potential predisposing factors and outcomes across studies. The variation of the type and definition of the potential predisposing factors examined across studies as well as the reduced number of articles identified which analyze the same factor (just one article in many cases), make the comparison between studies difficult and a meta-analysis impossible. Thus, it was not possible to reach consistent conclusions about the predisposing factors for back pain in children and adolescents.

Considering the physical/anthropometric factors, this review found conflicting evidence between age, gender, BMI and physical qualities.

These findings confirmed the results reported in other studies/ reviews $[4,55]$ suggesting a lack of evidence to support the value of these factors in the study of NSBP in children and adolescents

The same conclusion can be draw considering the association between lifestyles and behaviors and NSBP. The inconsistency in the findings founded in this review for the level and duration of physical activity contradicts previous reviews that had suggested that physical activity level/time of practice was a predisposing factor for the development of NSBP. Moreover, no association was found between the practice of physical activity or sports and BP [23,33].

Like in previous reviews, new data confirmed that there is no association between the family/social factors studied and NSBP. Contrariwise, several psychological and emotional factors showed significant associations with BP in children and adolescents $[26,30,40]$ However, based on this review no definite conclusions can be drawn due to design limitations. Psychological and emotional factors of varying nature inhibit a more definitive conclusion about the potential relevance of these factors to the BP. Moreover, the studies were few in number and were of poor quality. Psychological and emotional factors require more rigorous investigations to determine their relationship with NSBP in this population. 
Finally, this review's findings founded that several different mechanic factors have showed statistically significant associations with NSBP, namely the school bag carrying time [21], carrying the bag on one shoulder [40], twisting the back for more than 10 min during the lesson/class [8] and the position and time spent watching television, or doing the homework [34]. However, these findings were based on one or two studies and no definitive conclusion can be draw.

In summary, the findings of this review emphasize a lack of evidence to support or refute the association between back pain and the different predisposing factors reported in the literature.

\section{Conclusion and Implications for Clinical Practice}

The results of this systematic literature support the high prevalence of NSBP in young population and corroborate the current idea that NSBP is an important clinical condition at this age.

The scarcity and conflicting evidence of the research findings about potential predisposing factors and the methodological flaws identified in the studies limited a more consistent conclusion of this review. Future research should concentrate both on case definition and on improving the methodological quality of the studies. The use of a standardized definition of NSBP is a recommendation endorsed by a recent international consensus $[53,54]$ to enable better comparisons between countries, and ultimately lead to a deeper understanding of this clinical condition in children and adolescents. Prospective studies are also needed to further clarify these unclear and conflicting results especially on predisposing factors that can be used by the health professionals in preventing NSBP through health programs.

\section{Acknowledgements}

The authors express their gratitude to Mr. Marco Jardim who shared his time and expertise in the initial steps of selecting the relevant studies.

\section{References}

1. Burton AK, Balagué F, Cardon G, Eriksen HR, Henrotin Y, et al. (2006) Chapter 2. European guidelines for prevention in low back pain: November 2004. Eur Spine J 15 Suppl 2: S136-168.

2. Hestbaek L, Leboeuf-Yde C, Kyvik KO (2006) Is comorbidity in adolescence a predictor for adult low back pain? A prospective study of a young population. BMC Musculoskelet Disord 16: 7-29.

3. Siambanes D, Martinez JW, Butler EW, Haider T (2004) Influence of school backpacks on adolescent back pain. J Pediatr Orthop 24: 211-217.

4. Balagué F, Troussier B, Salminen JJ (1999) Non-specific low back pain in children and adolescents: risk factors. Eur Spine J 8: 429-438.

5. Brattberg G (2004) Do pain problems in young school children persist into early adulthood? A 13-year follow-up. Eur J Pain 8: 187-199.

6. Sjölie AN, Ljunggren AE (2001) The significance of high lumbar mobility and low lumbar strength for current and future low back pain in adolescents. Spine (Phila Pa 1976) 26: 2629-2636.

7. Szpalski M, Gunzburg R, Balagué F, Nordin M, Mélot C (2002) A 2-year prospective longitudinal study on low back pain in primary school children. Eur Spine J 11: 459-464.

8. Murphy S, Buckle P, Stubbs D (2007) A cross-sectional study of self-reported back and neck pain among English schoolchildren and associated physical and psychological risk factors. Appl Ergon 38: 797-804.

9. Masiero S, Carraro E, Celia A, Sarto D, Ermani M (2008) Prevalence of nonspecific low back pain in schoolchildren aged between 13 and 15 years. Acta Paediatr 97: 212-216.

10. Elfering A, Mannion AF (2008) Epidemiology and risk factors of spinal disorders. In: Boos N, Aebi M (eds) Spinal disorders- fundamentals of diagnosis and treatment. Springer, Berlin.

11. Hill JJ, Keating JL (2009) A systematic review of the incidence and prevalence of low back pain in children. Physical Therapy Reviews 14: 272-284
12. McBeth J, Jones K (2007) Epidemiology of chronic musculoskeletal pain. Best Pract Res Clin Rheumatol 21: 403-425.

13. Taylor E, Boyer K, Campbell F (2008) Pain in hospitalized children: A prospective cross-sectional survey of pain prevalence, intensity, assessment and management in a Canadian pediatric teaching hospital. Pain Res Manag 13: $25-32$.

14. Grimmer K, Nyland L, Milanese S (2006) Longitudinal investigation of low back pain in Australian adolescents: a five-year study. Physiother Res Int 11: 161 172.

15. Jones GT, Macfarlane GJ (2005) Epidemiology of low back pain in children and adolescents. Arch Dis Child 90: 312-316.

16. Stroup DF, Berlin JA, Morton SC, Olkin I, Williamson GD, et al. (2000) Metaanalysis of observational studies in epidemiology: a proposal for reporting Meta-analysis Of Observational Studies in Epidemiology (MOOSE) group. JAMA 283: 2008-2012.

17. Jeffries LJ, Milanese SF, Grimmer-Somers KA (2007) Epidemiology of adolescent spinal pain: a systematic overview of the research literature. Spine (Phila Pa 1976) 32: 2630-2637.

18. Milanese S, Grimmer-Somers K (2010) What is adolescent low back pain? Current definitions used to define the adolescent with low back pain. J Pain Res 3: 57-66.

19. Law M, Stewart D, Pollock N, Letts L, Bosch J, et al.(1998) Guidelines for Critica Review Form-Quantitative Studies. [http//www.srsmcmaster.ca/Portals/20/pdf/ ebp/quanguidelines.pdf]

20. Kohler CG, Walker JB, Martin EA, Healey KM, Moberg PJ (2010) Facial emotion perception in schizophrenia: a meta-analytic review. Schizophr Bull 36: 1009-1019.

21. Chiang $H$, Jacobs K, Orsmond $G$ (2006) Gender-age environmental associates of middle school students' low back pain. Work 26(2): 197-206.

22. Sato T, Ito T, Hirano T, Morita O, Kikuchi R, et al. (2008) Low back pain in childhood and adolescence: a cross-sectional study in Niigata City. Eur Spine J 17: 1441-1447.

23. Bo Andersen L, Wedderkopp N, Leboeuf-Yde C (2006) Association between back pain and physical fitness in adolescents. Spine (Phila Pa 1976) 31: 17401744.

24. Ayanniyi O, Mbada CE, Muolokwu CA (2011) Prevalence and profile of back pain in Nigerian adolescents. Med Princ Pract 20: 368-373.

25. Cudré-Mauroux N, Kocher N, Bonfils R, Pirlet M, Meichtry A, et al. (2006) Relationship between impaired functional stability and back pain in children: an exploratory cross-sectional study. Swiss Med Wkly 136: 721-725.

26. Diepenmaat AC, van der Wal MF, de Vet HC, Hirasing RA (2006) Neck/ shoulder, low back, and arm pain in relation to computer use, physical activity, stress, and depression among Dutch adolescents. Pediatrics 117: 412-416.

27. Erne C, Elfering A (2011) Low back pain at school: unique risk deriving from unsatisfactory grade in maths and school-type recommendation. Eur Spine J 20: 2126-2133.

28. Geldhof E, De Clercq D, De Bourdeaudhuij I, Cardon G (2007) Classroom postures of 8-12 year old children. Ergonomics 50: 1571-1581.

29. Grimmer K, Nyland L, Milanese S (2006) Repeated measures of recent headache, neck and upper back pain in Australian adolescents. Cephalalgia 26: $843-851$

30. Heaps N, Davis MC, Smith AJ, Straker LM (2011) Adolescent drug use, psychosocial functioning and spinal pain. J Health Psychol 16: 688-698.

31. Jordaan R, Kruger M, Stewart AV, Becker PJ (2005) The association between low back pain, gender and age in adolescents. South African Journal of Physiotherapy 61: 15-20.

32. Kjaer P, Wedderkopp N, Korsholm L, Leboeuf-Yde C (2011) Prevalence and tracking of back pain from childhood to adolescence. BMC Musculoskelet Disord 12: 98

33. Mogensen AM, Gausel AM, Wedderkopp N, Kjaer P, Leboeuf-Yde C (2007) Is active participation in specific sport activities linked with back pain? Scand $J$ Med Sci Sports 17: 680-686.

34. Mohseni-Bandpei MA, Bagheri-Nesami M, Shayesteh-Azar M 
Citation: Robalo L, Cruz E, Nunes C (2015) Epidemiology of Non-Specific Back Pain in Children and Adolescents: a Systematic Review of Observational Studies. J Nov Physiother 5: 266. doi:10.4172/2165-7025.1000266

Nonspecific low back pain in $\mathbf{5 0 0 0}$ Iranian school-age children. J Pediatr Orthop 27: $126-129$

35. O'Sullivan PB, Straker LM, Smith A, Perry M, Kendall G (2008) Carer experience of back pain is associated with adolescent back pain experience even when controlling for other carer and family factors. Clin J Pain 24: 226-231.

36. Perry M, Straker L, O'Sullivan P, Smith A, Hands B (2009) Fitness, motor competence, and body composition are weakly associated with adolescent back pain. J Orthop Sports Phys Ther 39: 439-449.

37. Pellisé F, Balagué F, Rajmil L, Cedraschi C, Aguirre M, et al. (2009) Prevalence of low back pain and its effect on health-related quality of life in adolescents. Arch Pediatr Adolesc Med 163: 65-71.

38. Sato T, Ito T, Hirano T, Morita O, Kikuchi R, et al. (2011) Low back pain in childhood and adolescence: assessment of sports activities. Eur Spine J 20 : 94-99.

39. Trevelyan FC, Legg SJ (2010) The prevalence and characteristics of back pain among school children in New Zealand. Ergonomics 53: 1455-1460.

40. Trevelyan FC, Legg SJ (2011) Risk factors associated with back pain in New Zealand school children. Ergonomics 54: 257-262.

41. Wedderkopp N, Kjaer P, Hestbaek L, Korsholm L, Leboeuf-Yde C (2009) Highlevel physical activity in childhood seems to protect against low back pain in early adolescence. Spine J 9: 134-141.

42. Auvinen J, Tammelin T, Taimela S, Zitting P, Karppinen J (2008) Associations of physical activity and inactivity with low back pain in adolescents. Scand J Med Sci Sports 18: 188-194.

43. Auvinen JP, Tammelin TH, Taimela SP, Zitting PJ, Järvelin MR, et al. (2010) Is insufficient quantity and quality of sleep a risk factor for neck, shoulder and low back pain? A longitudinal study among adolescents. Eur Spine J 19: 641-649.

44. Auvinen JP, Tammelin TH, Taimela SP, Zitting PJ, Mutanen PO, et al. (2008) Musculoskeletal pains in relation to different sport and exercise activities in youth. Med Sci Sports Exerc 40: 1890-1900.
45. Hakala PT, Rimpelä AH, Saarni LA, Salminen JJ (2006) Frequent computerrelated activities increase the risk of neck-shoulder and low back pain in adolescents. Eur J Public Health 16: 536-541.

46. Korovessis P, Repantis T, Baikousis A (2010) Factors affecting low back pain in adolescents. J Spinal Disord Tech 23: 513-520.

47. Mikkonen $P$, Leino-Arjas $P$, Remes J, Zitting $P$, Taimela $S$, et al. (2008) Is smoking a risk factor for low back pain in adolescents? A prospective cohor study. Spine (Phila Pa 1976) 33: 527-532.

48. Roth-Isigkeit A, Thyen U, Stöven H, Schwarzenberger J, Schmucker P (2005) Pain among children and adolescents: restrictions in daily living and triggering factors. Pediatrics 115: e152-162.

49. Skoffer B (2007) Low back pain in 15- to 16-year-old children in relation to school furniture and carrying of the school bag. Spine (Phila $\mathrm{Pa} 1976) 32$ E713-717.

50. Turk Z, Vauhnik R, MicetiÄł-Turk D (2011) Prevalence of nonspecific low back pain in schoolchildren in north-eastern Slovenia. Coll Antropol 35: 1031-1035.

51. Yao W, Mai X, Luo C, Ai F, Chen Q (2011) A cross-sectional survey of nonspecific low back pain among 2083 schoolchildren in China. Spine (Phila Pa 1976) 36: 1885-1890.

52. Kaspiris A, Grivas TB, Zafiropoulou C, Vasiliadis E, Tsadira O (2010) Nonspecific low back pain during childhood: a retrospective epidemiological study of risk factors. J Clin Rheumatol 16: 55-60.

53. Dionne CE, Dunn KM, Croft PR, Nachemson AL, Buchbinder R, et al. (2008) A consensus approach toward the standardization of back pain definitions for use in prevalence studies. Spine (Phila Pa 1976) 33: 95-103.

54. Bernstein RM, Cozen H (2007) Evaluation of back pain in children and adolescents. Am Fam Physician 76: 1669-1676.

55. Cardon G, Balagué F (2004) Low back pain prevention's effects in schoolchildren. What is the evidence? Eur Spine $\mathrm{J} 13: 663-679$
Citation: Robalo L, Cruz E, Nunes C (2015) Epidemiology of Non-Specific Back Pain in Children and Adolescents: a Systematic Review of Observational Studies. J Nov Physiother 5: 266. doi:10.4172/2165-7025.1000266
Submit your next manuscript and get advantages of OMICS Group submissions

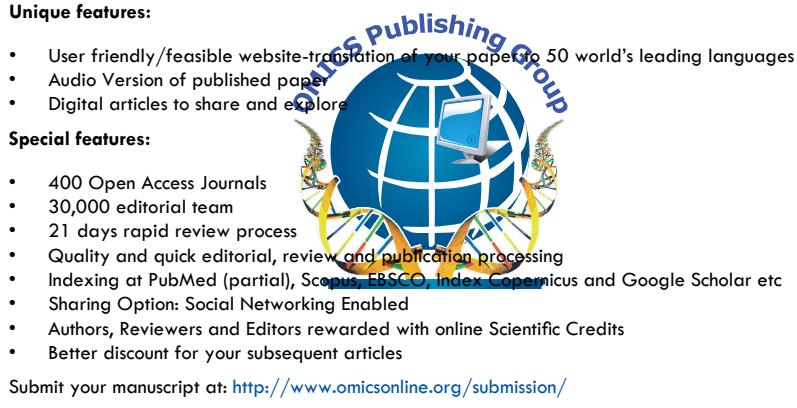

